\title{
Pesca artesanal, economía e intermediación en litoral del sur austral chileno. Un análisis histórico-etnográfico con perspectiva latinoamericana
}

\section{Artisanal fishing, economics and broking arrangements along the coast of austral Chile. A historical-ethnographic analysis from a Latin American perspective}

Gonzalo Saavedra Gallo ${ }^{1}$ https://orcid.org/0000-0002-8360-4939

Magdalena Navarro Pacheco ${ }^{2}$ https://orcid.org/0000-0003-1502-6767

${ }^{1}$ Universidad Austral de Chile, Facultad de Filosofía y Humanidades, Instituto de Estudios Antropológicos. Centro de Investigación Dinámica de Ecosistemas Marinos de Altas Latitudes, IDEAL, Valdivia, CHILE. Email: gonzalo.saavedra@uach.cl

${ }^{2}$ Universidad Austral de Chile, Facultad de Filosofía y Humanidades, Instituto de Estudios Antropológicos, Valdivia, CHILE. Programa de Doctorado en Antropología, Universidad Católica del Norte, CHILE. Becaria Agencia Nacional de Investigación y Desarrollo (ANID), Programa de Formación de Capital Humano Avanzado/ Beca Doctorado Nacional 2018 21180864. Email: mnavarro@uach.cl

\section{Resumen}

En este artículo partimos analizando la relación que históricamente establecieron las y los habitantes del litoral sur austral chileno con agentes económicos-empresarios o intermediarios- que al menos desde el siglo XIX demandaron la explotación de recursos naturales abundantes en estas latitudes, principalmente maderas, pieles de mamíferos y pesquerías. El trabajo, de base etnográfica, deriva hacia la problematización de las condiciones actuales y/o contemporáneas de estas dinámicas relacionales, fuertemente arraigadas, bajo la figura consagrada de la intermediación, factor crítico en los sistemas pesquero-artesanales.

Palabras claves: Pesca artesanal, intermediarios, habilitación, sur austral de Chile.

\begin{abstract}
In this article we start by examining the relationship established historically by the inhabitants of the coast of austral Chile with economic agents - entrepreneurs or brokers - whose demand stoked exploitation of the abundant natural resources of this area, mainly wood, mammal skins and fish, from at least the middle of the nineteenth century. The work, based on an ethnographic study, leads up to the problematisation of the current and/or contemporary state of the dynamics of these strongly rooted relationships, in the time-honoured form of brokerage, a critical factor in artisanal fishing systems.
\end{abstract}

Keywords: Artisanal fishing, intermediaries, material support, austral Chile.

Recibido: 21 julio 2017. Aceptado: 19 octubre 2018 


\section{Introducción}

El arraigo social del extractivismo en los sistemas de pesca artesanal tiene un fuerte componente histórico-cultural; es decir, se ha naturalizado en la costumbre, en la recurrencia de los saberes prácticos y en la producción de sentidos que la consagran. Esta lógica se encuentra altamente presionada por los mercados exportadores y la presencia de intermediarios en el primer eslabón de la cadena de valor, constituyendo así los dos ejes críticos de estas economías tanto en Chile como en toda Latinoamérica. El propósito de este artículo es analizar, desde una perspectiva comparada, los condicionantes económico-culturales y político-culturales de tres espacios litorales de predominio pesquero-artesanal en territorios significativos en el sur austral de Chile (en las regiones de Los Lagos y Aysén), en particular en el marco de sus procesos productivos y comerciales suscitados en los últimos años. Complementariamente, se establecerán puntos de referencia con otros casos similares a nivel nacional y latinoamericano.

La línea argumental del artículo deviene en el análisis de las dinámicas relacionales de apropiación extractivo-productivo del territorio y especialmente de las relaciones estructurales que estos sistemas establecen con el mercado -local, nacional y de exportación-; en particular las observadas en los procesos de intermediación comercial. Preliminarmente observamos la intermediación en la figura del trader o comerciante, agente que enlaza los procesos de intercambio y de ello obtiene un beneficio material. Ambas dinámicas relacionales, con el espacio-territorio y con los intermediarios, presuponen arraigos que escapan a las explicaciones estructuralmente más deterministas y exógenas. De este modo, el análisis se posiciona en un concepto de "relación estructural" antropológicamente más amplio, que reconoce la condición históricamente construida de las asimetrías relacionales, pero asimismo las observa ideacionalmente amalgamadas, en lo profundo de su materialidad (Godelier, 1990), y espacialmente localizadas.

\section{La problemática}

Definiremos dos dimensiones problemáticas de los sistemas pesquero-artesanales. La primera es la di- mensión productivo-ambiental, referida a su condición de sistema con predominio extractivista y fuertemente constreñido por el mercado. Esta condición tiende a situar las economías pesquero-artesanales en el límite de la insustentabilidad (Cunningham y Bostock, 2005). La segunda dimensión, referida al intercambio, deriva de la anterior. Advertimos que en estas economías son frecuentes las figuras de intermediación, pudiendo sostenerse que los intermediarios ejercen una presión estructural que tensiona la base material hacia el sobreesfuerzo extractivo. Se trata de un mismo problema observado en dos momentos distintos. De forma esquemática diremos lo siguiente: Las economías litorales, basadas en la pesca artesanal están inmersas en dos tipos de constricciones relacionadas entre sí. Por una parte son extractivistas y por otra sus procesos de intercambio comercial se encuentran en manos de intermediarios. El extractivismo puede leerse como expresión de su propia historia, en sus diversas cristalizaciones territoriales, pero también como expresión de su identidad económica. Es decir, sin prácticas de extracción no habría pesca artesanal. En otros términos, es condición socioambiental cuyo anclaje es histórico-cultural. Sin embargo -sostenemos- la intermediación se ha institucionalizado en la pesca artesanal, a partir de un dinamismo de mayor complejidad. Por una parte cabría pensar en una lógica de "articulación" (Comas d'Argemir, 1997), donde las economías del lugar se subordinan a la fuerza expansiva del capitalismo; pero por otra parte, a nivel interno, en las sociedades litorales se han "naturalizado" determinadas representaciones que condicionan de ese modo específico las relaciones de producción (Godelier, 1990).

Desde un punto de vista histórico, el lugar de los mercaderes o comerciantes es decisivo en los albores del capitalismo (Braudel, 1985; Polanyi, 2009). Sus expresiones han sido diversas en el curso del tiempo y de acuerdo a los múltiples contextos en los que ocurren; por ello, no debe extrańar que en los espacios de pesca artesanal los traders sean parte de las comunidades (Pollnac, 1995), diferenciándose en procesos de estratificación vinculados a posiciones estratégicas en el mercado (Neira, 2005; Thompson, 2007; Sáez, Adofacci y Maino, 2012). En otro plano, no es posible soslayar el condicionamiento que ejercen los agentes del mercado sobre los precios, 
en especial en una economía tan liberalizada como la chilena (Harvey, 2007), y cómo ello deviene en impactos sustantivos en los eslabones primarios de la cadena de valor. De hecho, en estas dinámicas de intermediación, es posible advertir cómo, en espacios económicos con anclajes identitarios diferenciados, tiene lugar, de forma creciente, la acción oportunista de "finders-keepers" que se apropian no solo del valor material sino también de los inmateriales (Macías y Alonso, 2015). Podríamos ver en ello una expresión particular de lo que Comaroff y Comaroff (2011) denominaron "economía de la identidad”.

El problema del extractivismo y de la intermediación en las economías pesquero-artesanales da cuenta de la fuerza instituyente de la estructuración social (Bourdieu, 1980; Appadurai, 2015), pero a su vez son expresión de sus tensiones, y en ese marco permiten instalar la pregunta por los límites: ¿Pueden los sujetos locales trasponer los imperativos de esta fuerza estructurante?, ¿bajo qué condiciones? En principio, antes de pensar en esas respuestas, habría que demandar una perspectiva de complejidad en donde no solo importe superar la visión instrumental racionalista de lo económico (Hinkelammert y Mora, 2005), sino además admitir que es una complejidad sistémica (Wolf, 1987; Friedman, 1994; Wallerstein, 2005), en donde se entrelazan las dimensiones simbólico-culturales (Bird-David, 1997) y sociohistóricas (Hinkelammnert, 2001). Está implícita en esta problematización la pregunta por la racionalidad que gobierna las prácticas y moviliza las acciones. Formulado en plural, ¿qué racionalidades e incluso qué éticas nos permiten cualificar estos escenarios o espacios económicos?, ¿cómo entronca en ellos el problema de los límites?

En síntesis, nuestro análisis contempla, en primer término, las relaciones que, en cada uno de estos contextos, establecen las comunidades con el territorio y en concreto con el espacio base de su reproducción material, que es en este caso el espacio marino-costero. En segundo término, la relación de los intermediarios con los productores locales y su lugar en los sistemas costeros aquí referidos. Debemos advertir, sin embargo, que el foco del análisis estriba en este segundo eje del problema, siendo el primero parte del marco socioterritorial y ambiental en donde se sitúan las dinámicas relacionales etnográficamente abordadas en el texto.

En otro plano, nuestro eje de problematización teórico-conceptual estriba en la idea de economía. Partiendo de la tesis sustantivista de Polanyi (2009), sostenemos que lo económico es un proceso institucionalizado cuyo propósito último es asegurar la provisión de medios de subsistencia y la reproducción de la vida material, a través de la apropiación social del ambiente. Un segundo elemento que cabe rescatar del sustantivismo es su crítica a la falacia liberal, que ha universalizado el significado instrumental y psicologicista de la economía, de tal manera que se reduce a una relación lógico-racional entre medios escasos y fines alternativos. El primer componente que destacamos no ha estado exento de críticas, sobre todo teniendo en cuenta que toda institucionalización y/o estructuración de la vida social está sujeta a un conjunto de valores, ideas y significaciones (Bird-David, 1997), cuestión que relativiza la factibilidad de una lógica común en todas las instituciones. En este sentido, la clásica etnografía de Malinowski (2001) sobre el kula en las Trobriand sigue siendo una referencia obligada. La influencia del sustantivismo todavía es relevante, de modo que autores como Sahlins (1972, 1988), Gudeman (1990, 2000), Escobar (1996, 2010) e incluso Godelier (1990) o Bourdieu (2003) han contribuido a resolver algunas de sus limitaciones. La influencia de Gudeman, sobre todo a través de Escobar, revitaliza y reformula el lugar de la base material en el estudio de las economías locales, pero atendiendo con especial agudeza a las significaciones que le dan sentido como fundamento de todo el sistema. Cree Gudeman que el modelo más apropiado para definir y estudiar las economías campesinas -y cabe extenderlo aquí a las pescadoras- es el modelo de "la casa" (the house), cuyo fin último es autorreproducirse en el tiempo (Gudeman y Rivera, 1990; Gudeman, 2000). El eje de esa reproducción es lo que Gudeman llamó "la base", referida en efecto a la base material que permite mantener la casa. El momento cultural en la tesis de Gudeman está dado por la compleja dimensión valórica y de significaciones que modela la base. Para Gudeman existen diversos modelos de economía, diversidad observable en las áreas rurales de Latinoamérica; modelos cuya diferencia estriba tanto en las estrategias concretas de 
reproducción de su materialidad (caza, recolección, cultivos, pesca, etc.) como en las significaciones que los propios sujetos les asignan.

La tesis de Gudeman nos reporta una contribución interesante, en tanto nos impele a observar las economías litoraleñas en y desde los hogares (la casa). Una consecuencia inmediata de este enfoque es observar lo económico desde dentro, desde el espacio doméstico, cuestión que además de volver al sentido aristotélico de la misma -el oikos-, nos permite visibilizar y entender el despliegue de estrategias diferenciadas, todas orientadas a la reproducción de la base. Si bien no todas esas estrategias se relacionan con la pesca artesanal, sostenemos, sin embargo, que en los escenarios seleccionados es la pesca artesanal la que articula los sentidos identitarios de esas economías. La perspectiva económica desde the house implica indagar en todas las estrategias que permiten la reproducción de la base, así como los sentidos ideosimbólicos que tienen para los actores del lugar.

Una segunda aportación al concepto de economía es la que rescatamos de Godelier (1990), quien reformula el mecanicismo simplista entre las dimensiones materiales e ideacionales de lo social y de lo económico. Godelier sostiene que en toda configuración social productiva la materialidad está construida de idealidad, siendo un error pensar que la dimensión material de los procesos económicos -así como las relaciones sociales que implican, por ejemplo en la producción o en el intercambio- ocurren de modo independiente, o viceversa. En este marco su tesis viene a fortalecer aquellas aproximaciones posculturalistas del sustantivismo, como la de Gudeman, y en Latinoamérica todas aquellas que declaran la cuestión territorial como ineludible (Escobar, 2010; Leff, 2010), pues no solo se trata de caracterizar la objetividad del "mundo material", sino especialmente las representaciones y significaciones, es decir, las ideas que naturalizan esas relaciones -entre los sujetos y entre estos y el territorio. Este segundo enfoque sobre lo económico nos ha reportado otra clave investigativa: en los espacios litorales es necesario desentrańar cómo los actores se representan el conjunto de sus relaciones, en especial aquellas que refieren al lugar de extracción (el mar, el fondo marino, el borde costero, tierra-campo), pero sobre todo respecto de las figuras de intermediación presentes en las dinámicas comerciales.
Una tercera aportación para situarnos en la idea de economía está vinculada con el problema de la racionalidad. Esta cuestión ya fue señalada por Polanyi (2009) y se aloja en el núcleo de la falacia económica. Concretamente es el problema del predominio sin contrapeso de una racionalidad con arreglo a fines -la racionalidad instrumental- des-subjetivada y deshumanizada. Entonces, a través de este prisma la economía, gobernada por esta racionalidad degradada -en el sentido weberiano-, es un campo de cálculos entre costos y beneficios monetarios, un campo en donde incluso es posible pagar por los efectos no deseados. En la discusión latinoamericana, este problema ha sido trabajado a propósito de las consecuencias de la modernización capitalista tardía y en particular de la expansión neoliberal (Morandé, 1987; Hinkelammert, 2001). Como sostuvo Jean Marie Domenach (1980), la crisis del desarrollo es la crisis de la racionalidad.

Es precisamente Hinkelammert quien formula un concepto sugerente para problematizar la economía desde la discusión sobre la racionalidad. Según el autor existirían dos lógicas básicas de la racionalidad (económica), que a su vez expresan su eficiencia en modelos concretos. Por una parte, una racionalidad instrumental -centrada exclusivamente en la relación medios-fines- predominante y que da lugar a un modelo de eficiencia fragmentaria; y por otra, una racionalidad reproductiva -subsumida, erosionada y subordinada a la anterior- que expresa modelos de eficiencia basados en el principio de reproducción de las fuentes de la riqueza. Es lo que Hinkelammert y Mora (2005) denominaron "economía para la vida". De esta aportación derivamos un tercer parámetro fundamental: las configuraciones económicas de la pesca artesanal a nivel local deben elucidarse según sus estructuras de racionalidad, las que ciertamente nunca son del todo puras. El concepto de hibridación es, con cierta cautela, oportuno para pensar que en los espacios económico-productivos de base rural, campesina, pescadora e incluso indígena, se intersectan de forma compleja una multiplicidad de lógicas (García Canclini, 1990).

Los elementos teórico-conceptuales hasta aquí referidos entroncan con una dimensión que es fundamental en nuestro análisis: la ambiental. De manera breve interesa sostener nuestra aproximación a la 
misma como parte de una concepción ideomaterial del territorio. Si bien territorio no es sinónimo de ambiente, sí es pertinente como espacio en donde lo ambiental se despliega y expresa. Concebimos el territorio como una construcción social, culturalmente configurada; es decir, se trata de un espacio simbolizado y que en esa simbolización condensa materia e idea en un mismo proceso. He ahí, por ejemplo, la idea de territorialización. Siguiendo a Godelier, cabe decir que, en tanto cultura, el territorio es expresión de una materialidad indisociable del conjunto de ideas que lo significan y representan. Los territorios, como espacios construidos intersubjetivamente en el tiempo, son lugares de diferencia. Escobar, en una aportación a tener en cuenta, ha pensado esa idea de diferencia desde la complejidad que la asocia a "una formación ecológica, cultural y socialmente única del lugar y de la región" (Escobar, 2010 , p. 40). En ese sentido, los territorios son irrepetibles e irreductibles a modelos únicos. Hay aquí una coincidencia importante con la tesis de Gudeman sobre los modelos de economía, o bien con Hinkelammert y la idea de una racionalidad para la vida, que por definición es diversa.

Esta última referencia es consistente con la visión de Leff $(1998,2010)$ y su apuesta por una racionalidad ambiental. Esta racionalidad sería el soporte para la construcción de "otra economía", cuestión fundamental para enfrentar la actual crisis ambiental basada justamente en la racionalidad moderna del crecimiento económico, y que encuentra un momento crítico y perverso en las dinámicas del intercambio y de la intermediación; al menos en algunas de sus expresiones más persistentes. Como en las perspectivas ya reseñadas, esta racionalidad ambiental tiene anclaje en procesos ecológicos, sentidos y valores del territorio, distintos a los que predominan en el capitalismo.

\section{Los condicionantes estructurales y la intermediación en el espacio económico rural latinoamericano}

La configuración temporal de las relaciones subordinadas nos permite reconocer y problematizar estructuraciones desiguales entre actores de un espacio económico heterogéneo. Cabría aludir a la subordinación funcional de las economías locales, de base rural-tradicional al capitalismo en su dinámica expansiva (Comas d'Argemir, 1997). En realidad esta sería la expresión estructural, es decir, relacional persistente, de la expansión capitalista en cualquiera de sus formas, o, en un sentido más general, la expansión de Occidente y la progresiva imposición de su "proyecto" civilizatorio modernizante (Wolf, 1987; Friedman, 1994), en esa perspectiva estamos inmersos en un proceso de occidentalización (Comas d'Argemir, 1997). Sin embargo, interesa aquí destacar que ese orden estructural asimétrico, aun teniendo un peso significativo, no es del todo determinante, y desde ese punto de vista interesa observar etnográficamente sus expresiones empíricas situadas en la intersubjetividad, y metodológicamente desplegadas en la interfaz social (Long, 2007). Se entiende entonces que las relaciones de intercambio comercial son relaciones mediadas por esa asimetría estructural que algunos han denominado articulación pero que a nosotros nos interesa matizar. Esta dialéctica del intercambio desigual define estructural e intersubjetivamente las economías "tradicionales" latinoamericanas, estructuralmente en tanto configuración societal macro, tal vez en el sentido del campo -de la economía- en Bourdieu (2003), e intersubjetivamente porque a nivel microsocial tiene una expresión entre sujetos que reproducen cierta dinámica relacional colonial. Esto también es decisivo, al ser las economías costeras, de base rural-tradicional, configuraciones de base colonial, al menos desde un punto de vista histórico. Latinoamérica aparece como una región marcada por el proyecto colonial, en donde la explotación de la naturaleza y su instrumentalización son casi un rasgo identitario de la dependencia, y que además define esa relación que se produce entre el explotador (conquistador, encomendero, hacendado, empresario, comerciante, etc.) y el explotado (indígena, inquilino, trabajador, campesino, pescador, etc.). Incluso, luego visible en el concepto de "colonialismo interno", en tanto dinámica relacional extractivista que ocurre al interior de los Estados y que marca la historia social latinoamericana (González Casanova, 2006). Desde una perspectiva más reciente, pensaríamos en problematizar los espacios económicos locales como lugares silenciados, invisibilizados, en último término, obliterados como lugares de diferencia en la colonialidad del proyecto moderno (Mignolo, 2003). 
La pregunta que surge a partir de la crítica decolonial es hasta dónde es posible sostener y situarse en espacios de diferencia del todo distantes de los contenidos de la modernidad. Como ya indicamos, más pertinente es plantear un límite de hibridación, en donde las diferencias son constitutivas de economías locales y en donde las racionalidades se combinan y mixturan pero sin dejar de expresar las asimetrías propias del proyecto civilizatorio moderno.

En el análisis de las relaciones comerciales de intermediación destaca su expresión en diversos contextos rurales, en especial en las economías campesinas. Los estudios tienden a refrendar que la posición estructuralmente subordinada de los productores locales se despliega respecto de los comerciantes mayoristas y, en no pocos casos, respecto de los oligopolios que cada vez más controlan el acceso a los mercados (Torres Salcido, 2013). Esta dinámica ha sido detectada en todas las zonas rurales de Latinoamérica, pero matizando algunas diferencias. Por ejemplo, en México, la producción de quesos revela el lugar dinamizador de los intermediarios en la cadena de valor, según Castañeda et al. (2009); mientras que otros autores subrayan el perjuicio que estas dinámicas presuponen para los productores locales, en particular en cuanto al castigo de los precios de venta (Rebollar et al., 2011; Grass, Cervantes y Altamirano, 2013). En Colombia los investigadores retratan que la dinámica comercial de las economías campesinas está estrechamente asociada a los intermediarios (Rementería, 1981; Forero, 2012), advirtiendo el perjuicio que ello implica a nivel local (Sandoval y Ruiz, 2006). En Bolivia se ha estudiado la articulación entre campesinos y mercados en el espacio de las ferias rurales, también con una notable presencia de intermediarios (Elías y Devissche, 2014). Estos casos explicitan un límite recurrente para los productores locales: las dificultades de acceso y/o transporte desde los espacios de producción hacia los mercados de venta y consumo.

Pero la intermediación debe matizarse según escala y sentido territorial. Una cosa son los oligopolios y los grandes intermediarios que operan con volúmenes significativos de capital, sosteniendo un control en el eslabón primario de la cadena de valor, y otra cosa son las dinámicas de intermediación a escala local. A su vez debe diferenciarse, por una parte, al comerciante local que entra en el negocio sin formar parte del eslabón productor; $y$, por otra, tener en cuenta los intentos de los productores locales organizados -por ejemplo en asociaciones gremiales, cooperativas o sindicatos- que ampliando sus "funciones" más allá de lo social entran directamente en la intermediación. Sin embargo, por sobre las diferencias y las similitudes, los diversos estudios indican que los productores campesinos, y rurales en general, quedan fuertemente sujetos al poder de los intermediarios.

\section{Intermediación y sociedades litorales}

La presencia de intermediarios es patente en los sistemas de pesca a pequeña escala. Los análisis provienen de estudios de caso en diversas latitudes, con diagnósticos similares: dificultades para acceder a los mercados de exportación y consumo, escasa información, problemas de transporte y almacenamiento -en este caso en frío-, limitado capital de trabajo, entre otros factores que refuerzan las relaciones de dependencia y que juegan a favor de los intermediarios. Ahora bien, como se ha indicado en el caso de los campesinos, también en los sistemas de pesca artesanal cabe diferenciar, por una parte, a la gran intermediación oligopólica $-\mathrm{O}$ bien a esa intermediación que aun siendo de menor capitalización es ajena a los espacios locales-, de las dinámicas de intermediación que se entretejen en las mismas comunidades o sociedades litorales (Pollnac, 1995). Estas dinámicas locales obedecen a distintas lógicas e intereses; desde expresiones de estratificación interna, en donde algunos líderes y emprendedores de la comunidad terminan por instalarse en el lugar de los intermediarios o acopiadores (Boivin y Rosato, 2011), y tienden a funcionar con la misma lógica, hasta expresiones colectivistas similares, como sucede en el caso de algunos sistemas agroalimentarios localizados. Como sea, la tendencia es observar que la presencia de intermediarios es un problema recurrente en el eslabón de comercialización. Los ejemplos se presentan en contextos tan diversos e institucionalmente disímiles como España (Florido del Corral, 2008), Mauritania (Cunningham y Bostock, 2005), Senegal (Alioune y Catanzano, 2005), México (Marín, 2003; Pedroza y Salas, 2011), Argentina (Balbi, 2008), Brasil (Rodríguez Bravo, Montolla Vilar y 
Mas Manchón, 2011) o Uruguay (Acuña Plavan y Verocai, 2001), entre otros.

En 2016 constatamos, en el marco de tres registros etnográficos, la preponderancia de las dinámicas de intermediación en la costa del estado de Veracruz, México, en particular en la zona de Antón Lizardo, municipio de Alvarado. Nuestro trabajo de campo fue desarrollado en el litoral de El Bayo, un asentamiento subtropical, de clima cálido-húmedo, de baja densidad demográfica, cuya economía doméstica combina la pequeña ganadería, el cultivo de algunas especies vegetales, la prestación de servicios de taxi, las remesas de familiares migrantes en Estados Unidos y la pesca artesanal. Tal como sucede en otras latitudes latinoamericanas, la importancia de los intermediarios es estructuralmente decisiva. Son ellos quienes controlan el acopio y el almacenamiento de los peces en el puerto de Veracruz, principal nodo de distribución hacia otros mercados de consumo (Puebla y Ciudad de México). En este caso los acopiadores reciben directamente en el puerto, en donde disponen de cámaras de frío, o bien se trasladan a las áreas de pesca para recoger el producto. Aunque las cofradías de pescadores de El Bayo $\mathrm{y}$ otros asentamientos gestionan colectivamente el acarreo hacia Veracruz, el transporte y por supuesto el acopio en frío suponen una límitación que marca el lugar de unos y otros en la cadena de valor.

Lo que advertimos en la costa veracruzana es coincidente con otras observaciones realizadas en México, por ejemplo, en los estados de Chiapas (Alcalá, 1993), Michoacán (Marín, 2003) y Yucatán (Perea, 2016); o en Argentina, en la provincia de Entre Ríos (Balbi, 2008). Como señalamos más arriba, en todos estos casos, los intermediarios, fuera de disponer de capital de compra y capital de adelanto (activando el endeude), controlan ciertos componentes críticos del proceso, como el transporte y el almacenamiento. Es ese control el que consagra la persistencia de las relaciones de intercambio desigual, características de la intermediación.

En Chile las problemáticas se dan con matices dependiendo de los "recursos" y las zonas geográficas, no obstante, el diagnóstico es coincidente: los intermediarios tienen una presencia transversal en las economías rurales, con una importancia y fuerza notable en la pesca artesanal. Es el caso de pesquerías bentónicas y algunas demersales -como la merluza austral (Merluccius australis) - en Chiloé y Aysén, con destacables condiciones de "aislamiento" (Gajardo y Ther, 2011; Saavedra, 2011; Brinck, Plá y Morales, 2011). En caleta El Piojo, Niebla, Valdivia, a pesar de presentar buenas condiciones de conectividad y acceso a información, el lugar de los intermediarios ha sido recurrente (Ávalos, 2006). Algo más al norte, en la caleta de Queule, Neira (2005) detecta que los vínculos entre intermediarios ("comerciantes" en su investigación) y pescadores -o comunidadestrasponen lo meramente formal. En este caso han sido parte del sindicato o son vecinos de la localidad y los vínculos implican otros aspectos sociales. Esto es similar a lo advertido en la provincia del Huasco (caleta Los Bronces) por Marín (2007), y que nosotros, siguiendo a Pollnac (1995), también observamos en las costas insulares del Reloncaví (Cochamó), Chiloé y Aysén (Saavedra, 2011). En el norte, por ejemplo en Los Vilos, el mercado de las algas pardas (entre ellas el huiro-Macrocystis pyriphera; Macrocystis integrifolia) ha operado históricamente del mismo modo, con intermediarios que "compran" o "reciben" las capturas en playa. Incluso en figuras de comanejo y cultivo, como Áreas de Manejo y Explotación de Recursos Bentónicos (AMERB) y concesiones de acuicultura artesanal, se reproduce en parte esta dinámica (Ávalos, 2006; Gelcich, Edwards-Jones, Kaiser y Watson, 2005). Tampoco deja de ser llamativo que en caletas urbanas, sin mayores dificultades de acceso territorial a los mercados locales y regionales, como las de Valparaíso, se reproduzcan estas relaciones de dependencia (Zamora, 2011).

En este marco se advierte un cierto consenso -no siempre explícito o declarado abiertamente- respecto de la necesidad de "eliminar" al intermediario o al menos de solucionar los problemas que implica su figuración en la cadena de valor (De Laire, 2001). Por una parte, tal como ha sido destacado por Pollnac (1995) y también constatado en nuestra experiencia, esto no es tan sencillo si tenemos en cuenta que no pocas veces los intermediarios son parte de la propia sociedad litoral, a veces enlazados en relaciones de parentesco, y que además, sean o no parte de la comunidad, tienden a entretejerse vínculos personales que van más allá de lo propiamente formal. 
En otras palabras, los intermediarios son parte de la vida social de los territorios. Lo anterior permite subrayar que la intermediación -y las cadenas de valor en sí mismas- no pueden estudiarse exclusivamente en términos convencionales, incluyendo en esto ideas tan centrales como la "articulación" o la "subsunción”, pues nos conduciría únicamente a constataciones macroestructurales, posiblemente acertadas pero insuficientes. La dimensión cultural de la economía es teóricamente insoslayable (Escobar, 1996; Bird-David, 1997). Una perspectiva coincidente con este enfoque es la que nos propone Morales (2012), al analizar los itinerarios comerciales de la luga roja (Gigartina skottsbergii) y la merluza austral -partiendo por la intermediación- en Chiloé y Aysén. Siguiendo las aportaciones de Appadurai y Kopitoff, entre otros, el autor explora las dinámicas de transformación del valor de ambas pesquerías en el marco de sus vidas o biografías culturales (Appadurai, 1986), derivando en un análisis que en efecto trasciende los encuadres más funcionales e instrumentales de las mercancías.

La idea de "eliminar" al intermediario también ha estado presente a nivel de intervenciones, por ejemplo en programas de desarrollo local y territorial impulsados desde las agencias estatales y ONG. Cabe añadir que la idea también se encuentra discursivamente patente en las organizaciones locales, en particular en los sindicatos de pescadores. En este sentido, y a modo ilustrativo, una de las iniciativas más emblemáticas es la réplica en la zona costera de Valdivia del proyecto Lonxanet, impulsado por el antropólogo Antonio García Allut (García Allut y Vázquez Portela, 2012) en las cofradías gallegas. Lonxanet -vigente hasta 2011- fue un dispositivo de subastas de pesquerías a través de internet, cuya finalidad fue evitar las intermediaciones ajenas a la organización de pescadores. En el caso de Valdivia -Niebla- el proyecto ha sido impulsado por la Federación de sindicatos, FIPASUR (www.pescaenlinea.cl). Otra iniciativa interesante ha tenido lugar en Los Vilos, en donde recientemente -en el marco de una intervención que convocó a pescadores, agencias públicas y consultores- se logró establecer una red de comercialización y distribución no intermediada a restaurantes ubicados en Santiago; sin embargo aún es temprano para medir los resultados de esta inciativa.
Ahora bien, de modo alguno se apunta siempre a la eliminación de los intermediarios. Las visiones son matizadas, hay quienes sostienen que se trata de superar los monopolios y oligopolios para permitir el ingreso de nuevos agentes. O bien de buscar los equilibrios para favorecer la coexistencia virtuosa de unos y otros actores.

\section{Contexto histórico territorial, el sur austral de Chile}

Desde el punto de vista geográfico nos ubicamos en el territorio sur austral de Chile, el que situamos entre el seno de Reloncaví, región de Los Lagos, y la península de Taitao, región de Aysén. Nuestros referentes etnográficos son tres asentamientos pesqueroartesanales, correspondientes a las comunas de Las Guaitecas (Aysén), Quellón y Calbuco (Los Lagos). En el plano histórico-identitario, el territorio litoral del sur austral de Chile se encuentra significativamente vinculado al complejo sistema cultural que se ha entretejido en la isla de Chiloé. En términos clásicos podríamos hablar de un área cultural, en el sentido en que fue pensada por la escuela culturalista boasiana (Herskovits, 1954). Considerando esta premisa, Chiloé ha sido un foco de constantes influjos ideomateriales hacia el mar interior y hacia el sur, incluyendo toda la zona de Patagonia, en donde la influencia chilota ha sido patente (Martinic, 2005). La resultante de este proceso histórico ha sido el establecimiento de diversos espacios pesquero-artesanales y de economías bordemarinas, cuyos habitantes -en su gran mayoría- son herederos de las tradiciones mapuche-huilliche del sur de Chiloé, canoeras de los archipiélagos de Aysén, y por supuesto del mundo mestizo indígena, chileno y español que se constituyó en el mar interior. Existe entonces una historia cultural compartida que refleja diferentes espacios de interacción y movilidad simbólico-práctica asociadas a las comunidades litorales. En ellas las tradiciones económico-culturales, situadas en el lugar pero en interacción con agentes extralocales, son ejes identitarios decisivos para comprender los sistemas pesquero-artesanales. Por otra parte, también es fundacional el dinamismo de dichos espacios litorales suraustrales, existiendo registros de alta movilidad y translocalidad (nortesur; este-oeste) y espacios relacionales compartidos 
(De Beranger (1893) [1773]; Cavada, 1914; Otero, 2006; Urbina, 2011) que durante los siglos XIX y $\mathrm{XX}$ articulan diversas economías del lugar basadas en especies variadas (madera, pieles, pesquería deshidratada, conservería, pesquería bentónica, pesquería demersal e incluso salmonicultura).

Estas prácticas ocurren generalmente de manera complementaria y conforman economías litorales que integran de forma articulada recursos del mar y agroganaderos de pequeña escala (en algunos casos específicos, tal como sucede en Calbuco o la isla de Chiloé), alternando procesos de autoconsumo y venta. Además estos escenarios actualmente se enfrentan a diversas racionalidades y presiones ecológico-ambientales, ejemplo de ello es la presencia de industria acuícola con expresiones como la salmonicultura y mitilicultura (Barton y Román, 2016; Bustos e Irarrázaval, 2016), que sin duda reconfiguran estas estrategias tradicionales e históricas asociadas a la práctica y a los componentes ideacionales de las mismas.

\section{Estudios de caso, perspectiva comparativa}

\section{Materiales y método}

El material empírico fue recabado en tres etapas diferenciadas. La primera tuvo lugar entre 2002 y 2003 y corresponde a un trabajo etnográfico realizado en la zona insular del litoral de Aysén. Su marco referencial fue la realización de una tesis de licenciatura en antropología y de un proyecto Fondart sobre identidad y cultura en las islas Guaitecas y Huichas. De este trabajo obtuvimos 35 entrevistas semiestructuradas. La segunda etapa corresponde a un proceso etnográfico iniciado en 2004 y concluido en 2007, en donde se realizaron otras 21 entrevistas, esta vez enmarcadas en una tesis doctoral concluida en 2010 (Saavedra, 2011). Las entrevistas abarcaron testimonios de todo el litoral de Aysén y, en el marco de la primera crisis importante de zonas contiguas, se obtuvieron entrevistas en la comuna de Quellón. En la última etapa del proceso, desde el año 2011 a la fecha se realizaron más de 70 entrevistas y nueve grupos de discusión, enmarcados en tres proyectos de investigación (Fondecyt de Iniciación,
DID-UACh y Fondecyt Regular), situados espacialmente en diversas localidades costeras del sur austral (Figura 1). Para el caso de las entrevistas y los grupos de discusión se trabajó con un criterio de muestra estructural, cuya lógica es obtener una representación hermenéutica de los actores locales (Montañés, 2010).

Los estudios de caso que aquí se reseñan, como se ha indicado en la metodología, se enmarcan en un proceso de investigación de larga duración. El foco etnográfico principal ha estado en Las Guaitecas (región de Aysén), Quellón y Calbuco (región de Los Lagos), espacios costeros que son, desde el punto de vista pesquero-artesanal, altamente significativos en el sur austral de Chile (por estadísticas de desembarque y por tradición económico-productivocultural). En los tres casos se trata de sistemas con una notable importancia bentónica e incluso predominio de esta tradición identitaria, como ocurre en Quellón y Guaitecas. Esto es relevante pues la "tradición" bentónica podría asociarse remotamente a los primeros navegantes canoeros -hombres y mujeres- que habitaron y subsistieron en estos parajes, y que incluso estuvieron presentes en los siglos coloniales (Byron, 1955; García, 1889). Pueblos que efectivamente practicaron la recolección de mariscos pero también, y de modo significativo, la pesca de especies como el robalo (Eleginops maclovinus) para ahumado o la recolección de algas.

\section{Expresiones históricas del sistema de intermediación}

Los antecedentes históricos más relevantes y que, a nuestro juicio, inciden en el actual sistema de intermediación, parecen haberse configurado hacia la primera mitad del siglo XIX; aunque probablemente podamos remitirlos a las relaciones entre españoles e indígenas que se sucedieron en los primeros años de la conquista de Chiloé. En otro análisis (Saavedra y Navarro, 2016) hemos descrito lo que denominamos sistema de habilitación/endeude, es decir, la estructuración que expresa una relación de dependencia entre empresarios y comerciantes -en este caso de Chonchi, Ancud o de otras latitudes chilotas- y grupos de trabajadores, principalmente hacheros que eran trasladados desde el archipiélago 


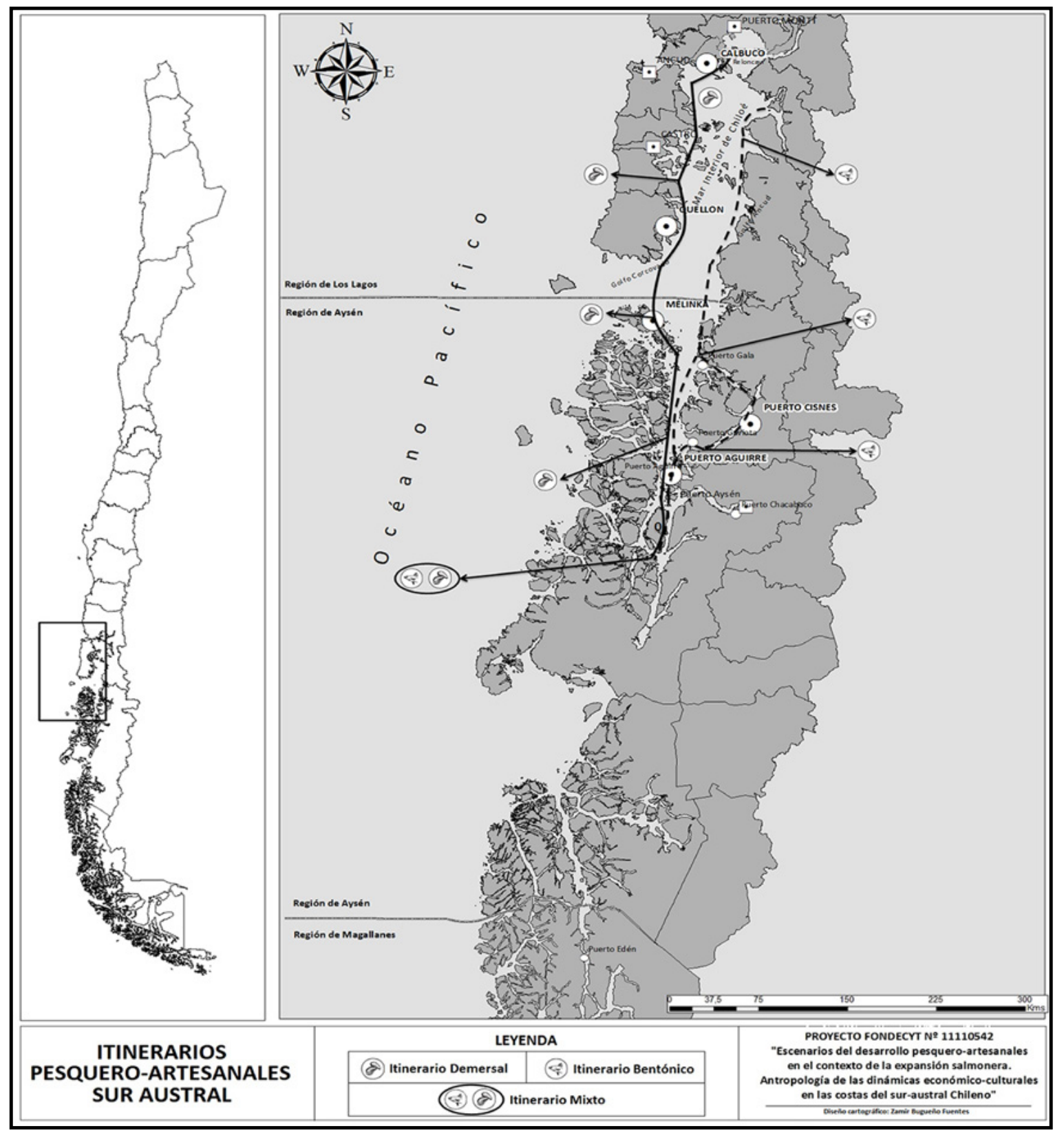

Figura 1. Mapa de itinerarios pesquero-artesanales contemporáneos, sur austral de Chile. Elaborado por Zamir Bugueño.

hacia los canales de la actual región de Aysén a las faenas del ciprés (Morales, 2014), y que posteriormente se hizo extensivo a otras faenas extractivas, en particular a la cacería de pieles y al ahumado de cholgas (Aulacomya ater) y pescado robalo (Núñez, Molina, Aliste y Bello, 2016). Entre las referencias históricas más significativas, y que se recogen en los textos citados, destacan las observaciones realizadas por el entonces capitán de fragata Enrique Simpson. Diego Morales nos ofrece una excelente síntesis al respecto:

En esa época, los comerciantes situados en Ancud actuaron como intermediarios frente 
a los agentes extra-regionales, pero no dominaron la explotación maderera, ya que fue asumida preferentemente por los dueños de embarcaciones que se distribuyeron en el interior del archipiélago de Chiloé. Esos madereros interiores organizaron in situ las expediciones de hacheros y el conjunto del tráfico entre las cordilleras del este, Guaitecas y la Isla Grande, así como del enganche de la población campesina, reclutada de las villas y villorrios mediante un sistema de deuda forzada consistente en el adelantamiento de alimentos (trigo, sal, agua ardiente) a cambio del compromiso a emplearse estacionalmente en las faenas madereras (octubre-marzo) (Morales, 2014, p. 42).

Los testimonios que presentamos a continuación, sostenemos, dan cuenta de la persistencia estructural del sistema relacional que observara Simpson en la segunda mitad del siglo XIX. Esta persistencia recrea condiciones variadas -según épocas, tipos de procesos extractivos y territorios- a lo largo del siglo $\mathrm{XX}$ y, como veremos más adelante, continúa vigente e incluso fuertemente arraigada en ciertos escenarios económico-productivos actuales.

Él traía todo y abastecia a su gente, [a la gente] que le trabajaba. Le traía de todo, harina, azúcar, hierba, de todo para que no le falte. Era difícil en esos años la vida... pasaba un barco cada quince días, una vez al mes. Mi papi siempre hablaba de [Enrique] Lagreze y [Ciriaco] Álvarez, que los habilitaban a ellos para que saquen el ciprés... les daban los viveres para que se vayan, póngale unos veinte dias a hacer esas piezas de madera afuera, fuera de aqui más a las islas. Siempre hacia el sur. $Y$ aqui mismo en Melinka que sacaban miles y miles de piezas de madera (Elsa, 2013, Puerto Melinka, Las Guaitecas).

El relato explica cómo los empresarios chilotes y otros afincados en la isla, a principios y a mediados del siglo XX continuaban proveyendo de víveres e insumos a las cuadrillas familiares, habilitándoles y endeudándoles a cambio de asegurar la entrega del producto. Es esa anticipación de insumos y víveres la que precisamente permite que el habilitador/intermediario obtenga, en prácticamente todos los acuerdos, la retribución por parte de la cuadrilla de pescadores, cazadores o taladores.

Por otra parte, es una expresión espacial del extractivismo que articula territorios distantes a través de la intermediación con barcos de remolque o acarreo ("un barco cada quince días"), agentes fundamentales para el traslado y concreción del proceso comercial asociado a la venta o posterior consumo del recurso explotado. En general, este y otros testimonios hacen referencia empírica a una situación planteada más arriba respecto de cómo las relaciones comerciales, asociadas a la intermediación, resuelven problemas elementales vinculados al transporte de los recursos explotados pero también a la disposición de elementos de primera necesidad para las familias y para las propias cuadrillas. Es decir, la intermediación plantea lecturas instrumentales diversas: existe una función de aprovisionamiento; pero a su vez, para las cuadrillas, esta modalidad articulación socioespacial resuelve el problema de traslado del recurso desde el nodo productivo localizado hacia los mercados de destino.

Es que nosotros íbamos a arrancharnos ahi y la gente de las lanchas nos llevaban los viveres, nos llevaban todo cuando nos faltaba. Las lanchas que nos iban a sacar los mariscos. Los fabricantes. Ponian la embarcación, supongamos todas las semanas iban las lanchas a buscar la mercadería... Después, cuando veníamos después de seis meses nos pagaban pero una miseria, no alcanzaba siquiera para vivir esos años... la comida lo llevaban de acá y después lo descontaban ellos. Los fabricantes eran terribles. Eran pero terribles. Se hacian, por decir, la plata con el bolsillo de la gente humilde que le trabajaba (Belisario, 2015, El Rosario, Calbuco).

En este testimonio se advierte que la espacialidad de las faenas no solo implicaba que los empresarios que intermediaban enviaban sus barcos o lanchas para acarrear los productos extraídos por cuadrillas conformadas en remotas latitudes (como Melinka); sino que también suponía el traslado de faenas o cuadrillas hacia esos territorios distantes. En este caso 
aparece una figura muy recurrente, también a principios y hacia mediados del siglo XX: los pescadores o loberos que se trasladan -con o sin familia- desde Calbuco a trabajar a Las Guaitecas o incluso más al sur, cerca de Puerto Aguirre en islas Huichas.

Resultan igualmente reveladores los tiempos de permanencia de las cuadrillas en los lugares de extracción. En el relato de Belisario L. se habla de "seis meses", temporalidades refrendadas en otras conversaciones y entrevistas, en donde se alude con frecuencia a temporadas de dos, tres, seis y hasta ocho meses trabajando en las faenas.

Pero estas dinámicas relacionales de habilitación, endeude e intermediación también fueron utilizadas en las faenas asociadas a las fábricas conserveras que desde fines del siglo XIX se instalan en Calbuco, Chiloé, Las Guaitecas y Huichas. La figura es muy similar y en sus principios de articulación es la misma:

$Y$ empezamos a trabajar [en la fábrica]... Los primeros dias trabajamos cinco días nomás y nos pagaron, nosotros le dijimos tienen que pagarnos [los] cinco dias trabajados para que saquemos viveres, entonces después ya nos pueden pagar en quince dias y asi fue; ese día nos arreglaron, ya sacamos plata, sacamos harina, cosas de comer, azúcar, hierba, de todo lo que necesita... tuvimos qué comer por nuestro trabajo (Luz, 2002, Puerto Melinka, Las Guaitecas).

El relato narra la intermediación directa en la fábrica o planta conservera. En realidad es una modalidad de comercialización o intercambio. Lo que cambia, insistimos, es la figuración coyuntural de la estructuración que venimos retratando hasta aquí. Lo interesante es que cobra una expresión particular según la cual la fábrica ocupa el lugar del empresario y del intermediario al mismo tiempo. En este esquema la habilitación, asociada a la intermediación, tiene una condición institucional peculiar, en la que se establece una relación ambivalente entre trabajadores locales (operarias y buzos) y empresarios. Por una parte se valoran las fuentes de trabajo, pero también se reconocen las lógicas de explotación de la fuerza de trabajo en que se reproduce la precariedad. Algo similar a lo que en la actualidad ocurre en relación a la industria salmonera.

Además, en este y otros testimonios sobre el período reseñado, destaca la referencia a la habilitación a partir de la entrega de víveres o alimentos necesarios, no solo durante el período y el lugar de la faena sino también para "dejar" en las casas de las cuadrillas mientras se realizan los largos períodos de extracción del recurso. "No era trabajo bien pagado. Dejaban pedido viveres para sus casas... Llevaban la habilitación para dos meses, para tres meses a la madera y dejaban habilitación para sus casas. Y para pagar esa habilitación... tenian que volverse a encalillar [con] los patrones..." (Luz, 2002, Puerto Melinka, Las Guaitecas).

Es necesario señalar aquí, en este punto en particular, que si bien hoy en día persiste -en algunas dinámicas económicas- la figura de la habilitación asociada a procesos de intermediación, esta ha adquirido un carácter instrumental vinculado a la implementación de la práctica productiva/extractiva, es decir, insumos, materiales e incluso dinero en efectivo que fluye desde el intermediario hacia el pescador o agricultor.

\section{Expresiones actuales del sistema de intermediación}

Como sostuvimos en la problematización que da lugar a este trabajo, y que ha sido nuclear en las investigaciones también reseñadas, la intermediación constituye un nodo crítico en las economías pesquero-artesanales en diversas zonas geográficas latinoamericanas y en toda la costa chilena. En realidad ni siquiera es un problema situado en esta región del planeta; es, sin lugar a duda, una condición propia del capitalismo. Los relatos que presentamos en este apartado revelan por un lado la persistencia temporal (contemporánea) de esta configuración, y por otro, sus variaciones territoriales, sobre todo en función del tipo de especie intermediada. Como en el apartado precedente, los casos provienen mayoritariamente del área sur austral de Chile (desde el archipiélago de Calbuco al sur). 
Los primeros testimonios corresponden a un grupo de conversación realizado en isla Quihua, Calbuco, en el año 2012. La pregunta abierta refería a los principales problemas de la pesca artesanal para los habitantes del sector San Antonio estero, un lugar emplazado a no más de $7 \mathrm{~km}$ de la ciudad de Calbuco. Uno de esos problemas fue justamente la figura de los intermediarios:

Nosotros trabajamos con intermediarios, no vendemos directo a ninguna planta. Trabajamos como sindicato en ese sentido, por un tema de tiempo y recursos también, porque el pescador está acostumbrado a tener dinero todos los dias, entonces eso es algo que dificulta el tema comercial, que no podamos nosotros mismos comercializar nuestros productos, entonces llega un intermediario que tiene recursos y te va pagando todos los días (buzo 1, Carlos).

Una vez juntamos dinero y le vendimos a una empresa, pero resulta que apareció un comprador que pagó un poquito más a los compañeros y por diez o veinte pesos quebraron el sistema, entonces también es un tema de compromiso, de confianza, para que las cosas resulten, por eso nosotros no logramos entregar directo a las plantas (buzo 2, Juan).

El intermediario es la persona que a ti te compromete, es la persona que siempre te está salvando, decimos nosotros. Por ejemplo, si tienes una pana él te pasa dinero, entonces estás obligado a entregarle (buzo 1, Carlos).

Se deja entrever aquí la dependencia de los pescadores respecto de los intermediarios, incluso bajo una modalidad actual del sistema de habilitación/ endeude, en donde existe una interrelación entre el momento productivo y el comercial que finalmente deriva en la entrega/venta del recurso. La relación estructural desigual es patente, pues el intermediario ocupa una posición económica marcadamente distinta a los demás participantes del proceso productivo y es capaz de mantener esa posición en el tiempo. Puede advertirse que, en la intermediación, la confianza es un factor crítico y al mismo tiempo un eje de vulnerabilidad del sistema pesquero artesanal. Es decir, hay condiciones objetivas -por ejemplo, disposición de capital- y subjetivas -por ejemplo, capacidad para sostener compromisos internos- que explican la persistencia de los sistemas de intermediación y sus variaciones en los territorios investigados.

Los intentos locales por intermediar también son frecuentes. En prácticamente todos los espacios de pesca artesanal es posible encontrar experiencias en donde son los mismos pescadores -dirigentes o no, a través de sindicatos o en forma particular- quienes buscan ocupar el lugar estructural del trader. Es lo que expresa el siguiente testimonio, obtenido en Puerto Melinka, Las Guaitecas, el año 2007.

\section{Después el resto de la gente se irá incorporan-} do a medida que vaya viendo que la cosa va funcionando, yo creo que la mayoría de los socios son reacios a cosas más comprometedoras porque la persona, los pescadores somos independientes, la persona tiene su embarcación, ir a trabajar y vender... están acostumbradas al intermediario, [pero] tienen que tener claro que ese grupo de personas o la organización que va a tener en sus manos, o a su cargo la planta de desconchadora, va a pasar a ser su intermediario para ellos también. A lo mejor va a sonar feo, ¿cómo el sindicato va a ser intermediario de sus propios socios?, pero de alguna manera sí, porque a la gente hay que traerle combustible, a la gente hay que darle los viveres, de repente hasta dinero, porque el intermediario trabaja asi porque nosotros en Melinka estamos acostumbrados a trabajar asi (dirigente de pescadores, 2007, Puerto Melinka, Las Guaitecas).

Los procesos de intermediación y de habilitación/ endeude a nivel local no son nuevos. De hecho algunos de los principales comerciantes y habilitadores de cuadrillas de loberos y cholgueros en el siglo XX fueron habitantes locales, "emprendedores" del lugar que ya en esos tiempos deciden invertir en embarcaciones y destinar recursos extra para sostener pagos anticipados. La figura de dirigentes y sindicatos (o asociaciones gremiales, como sucede más al norte en Los Vilos) intermediando la pesca es relativamente 
reciente y revela un proceso siempre latente y tensionante: la diferenciación y estratificación interna de la comunidades. Esto también debiéramos considerarlo como parte del retrato histórico del capitalismo, aspecto que ha sido referido por Wallerstein en sus investigaciones sobre el "intercambio desigual" y su impacto en las unidades domésticas semiproletarias (Wallerstein, 1998).

La eliminación de los intermediarios a través de las estrategias colectivas -sindicatos, cooperativas o asociaciones gremiales- ha demostrado un éxito relativo, más bien limitado. Pollnac, citando investigaciones realizadas en África occidental, sostiene que los principales factores que explican la resistencia de las propias comunidades frente a dicho proceso son, por una parte, las relaciones de parentesco entre pescadores e intermediarios, $y$, en segundo lugar, la importancia económica que tienen en el sistema (Pollnac, 1995).

En la cita del dirigente de Las Guaitecas aparece un tercer factor significativo y siempre referido en los testimonios: la costumbre ("la gente está acostumbrada a trabajar con intermediarios"). En otras palabras, existe una historia económico-cultural en el territorio que explica en parte el arraigo de sus prácticas y dinámicas relacionales, y por cierto su persistencia estructurante.

Estas observaciones, en particular los factores indicados, contrastan con las voces más críticas al interior de las organizaciones, cuestión que además da cuenta de diversas posiciones en la comunidad de pescadores respecto de si es o no es conveniente eliminar a los intermediarios de la cadena de valor. Es lo que sostiene Ch. H., dirigente de pescadores en Quellón, en Chiloé:

Ellos manejan el precio con la empresa y nos manejan... pero como dice el dicho: "la culpa no es del chancho, sino de quien le da el afrecho". Ellos nos dicen: "¿Necesitas plata? Toma, ahi tienes diez mil o veinte mil pesos", y uno se va a trabajar y cuando llega en la tarde ellos deciden cuánto nos van a cobrar en productos. Nos tienen manipulados, la idea sería sacar a esa gente de la empresa y que uno quede ven- diendo directamente a la empresa, eliminar al intermediario, porque ellos se ganan el dinero por uno (dirigente de pescadores, Quellón, 2013).

Es necesario insistir en la amplitud de referencias etnográficas sobre este dilema (con o sin intermediarios). Gran parte de las y los entrevistados considera que es una figura compleja, que detona controversias, y que además está cargada de matices. Por un lado solucionan problemas asociados a la comercialización, y por otro son los agentes beneficiados en la primera venta del recurso. En el siguiente testimonio pueden apreciarse con cierta claridad ambas expresiones: "Cuando usted va a trabajar ellos le pasan plata para bencina y todas las cuestiones, entonces como que tú amarras a alguien para entregar tu mercadería. Entonces después cuando tú vas a entregar tu mercadería ellos te ponen los precios, el buzo mariscador o los pescadores no colocamos los precios" (buzo mariscador, Pureo, Calbuco, agosto, 2017).

Lo que sostiene Pollnac -y lo que nosotros hemos advertido en los territorios litorales- revela precisamente que el intermediario es una figura que está institucionalmente incrustada en las economías de pesca artesanal, condición que no solo nos impele a una mirada sustantiva situada en una perspectiva que entronca con la tesis de Polanyi (2009), sino también en aquellas que dan cuenta de que esos arraigos también se entretejen en configuraciones ideosimbólicas del espacio local (Godelier, 1990; Bird-David, 1997).

En el sur austral, nuestra perspectiva de la economía no se limita exclusivamente a la pesca artesanal; en realidad estamos hablando de un sistema complejo e integrado que, al observarse desde la estrategia reproductiva de la casa (the house), cobra amplitud hacia otras dimensiones que contribuyen a la realización de la base material (Gudeman y Rivera, 1990). Y precisamente en estas otras dimensiones de la economía del lugar también se evidencian expresiones de la intermediación y -como podrá observarse-del sistema de habilitación/endeude. El siguiente relato, obtenido en mayo de 2017 en la isla de Chidhuapi en Calbuco, corresponde a un grupo de conversación realizado con familias pescadoras que desde 
hace algunos ańos se dedican al cultivo artesanal de choritos (Mytilus chilensis), producción que al igual que las pesquerías artesanales está fuertemente articulada a los mercados de exportación:

Nosotros nos unimos con una empresa española de Ancud, la Cataluña. Pusimos el cultivo y ellos ponen la plata, ellos vienen a cosechar, y después en la venta vamos mitad y mitad. Son convenios sin papeles... Entonces, por ejemplo, si este año no resulta... se van y se llevan la mitad de los flotadores, [pero] sigue siendo [mía] la concesión. El acuerdo con Cataluña es de palabra nomás, hicimos un contrato pero al final no lo firmamos. [Han respetado el contrato por diez años]. En febrero no vendimos porque estaban sacando ellos, porque tienen varios cultivos... tienen [cultivos con gente] por Hornopirén, por Chiloé, en varios lados (vecina isla Chidhuapi, 2017, Calbuco).

El testimonio refleja una expresión actual del proceso de habilitación/intermediación que, tal como vimos en el apartado referido a retratos históricos, se ha institucionalizado en el marco relacional -no formal- con una empresa o fábrica situada en el territorio. Una lógica de interacción que no es ajena al lugar ni a la costumbre, y que si bien permite ampliar los volúmenes de producción persiste en una articulación tradicional que realiza en una misma agencia la habilitación y la intermediación, en este caso con el mercado de consumo. Asimismo, vuelve a observarse aquí que la confianza es el factor decisivo en la estructura productiva y de intercambio.

En Calbuco, como en Chiloé, el sistema de habilitación/intermediación aparece también en la agricultura a pequeńa escala, que en no pocos casos es parte de la misma economía doméstica-familiar- en donde se sitúa la pesca artesanal. En el caso que citamos a continuación, el intermediario cumple un doble rol: es proveedor de recursos pecuniarios y comprador de la producción agrícola. De acuerdo a lo observado en el trabajo de campo y a la reconstrucción etnográfica de la conversación sostenida con el intermediario, la figura es la siguiente: él "presta" dinero para realizar las inversiones asociadas al trabajo agrícola, por ejemplo, para construir e implementar invernaderos. La lógica explicativa es que el gasto realizado por el productor primario es siempre superior a la inversión inicial, por lo tanto él como intermediario, mediante su participación en la cadena productiva, cubre parte importante de la inversión y permite que la familia pueda volver a producir, ya que nuevamente se realiza el préstamo de dinero. Es decir, es un ciclo continuo entre producción y comercialización. Aquí no se añade valor al producto, solo se trata de una habilitación/endeude y posterior venta intermediada del producto. Como sucede en los casos precedentes, la confianza vuelve a ser uno de los ejes principales de la articulación del sistema: "la gente confía en él y él en la gente, esa es la base de sus redes de comercialización" (nota de campo El Rosario, Calbuco, septiembre 2016).

\section{Perspectiva comparativa}

Los trabajos de campo realizados en el curso del año 2017, principalmente en Calbuco, nos han permitido establecer diferencias y similitudes significativas con lo observado anteriormente en Chiloé y en Aysén. Algunos ejes diferenciadores son los tipos de recursos (variedad), los tipos de intermediación y la articulación a mercados de distribución/consumo en escalas diversas.

En Las Guaitecas se advierte que la articulación a los intermediarios ha sido estructuralmente persistente y predominante. En este caso, al igual que en otras zonas del sur austral distantes de los centros de acopio y maquila, observamos una tendencia histórica a concentrar las capturas según las demandas de mercados externos. Por ejemplo, en el siglo XIX y parte del XX la tala del ciprés fue la base de la actividad extractiva y comercial; en la primera mitad del siglo XX es relevante la cacería de lobos marinos y nutrias, o más tarde la demanda de bivalbos que se procesaban en las plantas de Chiloé y Calbuco. En la actualidad, y desde fines de la década del ochenta, la base bentónica de la economía pesquero-artesanal de Las Guaitecas la constituye la captura y comercialización del erizo (Loxechinus albus), un recurso altamente demandado por los mercados asiáticos. Como ha sucedido desde mediados del siglo XIX con otros recursos, la primera venta del erizo y de otras capturas de temporada (luga roja y almeja 
(Venus antiqua)) está practicamente en su totalidad controlada por intermediarios-habilitadores.

En Quellón el escenario es distinto, aunque no radicalmente. Constatamos una mayor diversidad de recursos capturados (destacando luga roja, almeja, culengue (Gari solida), pulpo (Octopus vulgaris), erizo y congrio dorado (Genypterus blacodes)), una mayor conectividad vial y acceso a mercados de proximi$\mathrm{dad}$, incluyendo plantas de proceso, y por supuesto consumidores locales. En principio suponíamos que la figura de los intermediarios sería menos relevante en la estructura comercial, no obstante, más que recurrir a sistemas de comercialización directa, aparecen más alternativas de intermediarios. En este caso, a nivel comercial, la situación es similar a lo que sucede en Las Guaitecas, es decir, la variedad de recursos que demandan los mercados es limitada, el volumen de desembarques es relativamente alto y los intermediarios ejercen un control importante en la primera venta. En parte, esto se explica porque es en Quellón -situado en la frontera marítima entre Chiloé y Aysén- donde se entretejen las relaciones de intermediación que operan en el archipiélago de Las Guaitecas y en otras zonas del litoral insular de Patagonia.

Siendo un espacio archipelágico culturalmente similar a los anteriores, en Calbuco advertimos dinámicas de intermediación distintas y, hasta cierto punto, más variadas. De acuerdo a lo que pudimos advertir en una encuesta de caracterización económicocultural aplicada en 2017, se capturan al menos 40 recursos pesquero-artesanales, destinados tanto al mercado como al autoconsumo. Por supuesto que en Las Guaitecas y en Quellón la provisión para el sustento familiar también incluye una variedad importante de recursos, sin embargo en Calbuco las expresiones del mercado son relevantes en los cuatro niveles: locales, regionales, nacionales e internacionales. Esto implica que una fracción de esos productos son derivados (con y sin intermediación) a mercados de proximidad, en el mismo puerto de Calbuco y también en la ciudad de Puerto Montt. En ambos casos los mercados localizados tradicionales permanentes (por ejemplo, Angelmó o mercado municipal del Calbuco) favorecen que otro tipo de pesquerías (y productos agrícolas) tengan circulación más allá del consumo familiar. Estas distintas escalas de mercado, especialmente en la escala local, dan lugar a la venta directa y otras lógicas de intermediación, por ejemplo, agentes de las propias comunidades que emprenden este oficio.

Tal como sucede en Las Guaitecas y Quellón, el lugar de los intermediarios (incluso habilitadores) es estructuralmente decisivo en cuanto a pesquerías destinadas a mercados nacionales distantes y a mercados internacionales (previo proceso de maquila en planta). Es probable, en contrapartida, que la condición geográfica de Quellón y especialmente de Las Guaitecas explique que en ambos escenarios la participación de intermediarios locales, aun cuando existe, sea proporcionalmente menor, puesto que el acceso a mercados de proximidad también es más limitado. Y en el caso de Las Guaitecas, inexistente.

\section{Conclusiones}

La intermediación pareciera ser una condición estructural de los sistemas pesqueros artesanales del sur austral de Chile. Si bien aquí hemos presentado referencias de tres espacios económicos localizados, esta dinámica es posible de advertir y constatar en otras latitudes, no solo en el territorio en cuestión sino en diversas zonas de la costa chilena y latinoamericana. Nuestras recientes investigaciones en las áreas litorales de Valdivia y Los Vilos, en Chile, y en la costa de Veracruz, en México, refrendan esta observación. Pero también, como ha sido registrado en literatura muy diversa -reseñada en este trabajo-, la intermediación, en los términos por nosotros descrita, está presente en otras configuraciones económico-culturales, en otras economías. Sin duda que, en este sentido, es relevante tener en consideración las variables históricas que explican la genealogía colonial de esas dinámicas relacionales, muy propias de las sociedades latinoamericanas. Ciertamente, el devenir temporal de las economías litorales del sur austral -retratadas en los casos de Las Guaitecas, Quellón y Calbuco- revelan tal condición. Y más aun, nos permite rastrear y evidenciar que la intermediación está profundamente arraigada en un sistema que en nuestros últimos trabajos -incluyendo este- hemos denominado sistema de habilitación y endeude; el que, dicho sea de paso, ha sido estudiado por otros autores en Chile y también en otros 
países de la región. Estas últimas consideraciones denotan la importancia de entender y problematizar la intermediación en su dimensión histórica, cuestión que indica que no solo es condición estructural -característica de las economías capitalistas y de las lógicas de articulación-, sino que es sobre todo condición histórico-estructural.

La persistencia de la intermediación remite, sin duda, a relaciones estructurales que desde el punto de vista económico convencional podemos asociar a diferenciales de capital. Es decir, los pescadores $-\mathrm{y}$ sus familias- quedan sujetos a las condiciones de los intermediarios y/o intermediarios habilitadores (en un registro más bien histórico) debido a que no poseen los recursos suficientes para sostener su reproducción de vida material. En efecto, eso parece etnográficamente indiscutible; sin embargo, en prácticamente todos los casos se observa que existen aspectos ideosimbólicos e ideomateriales que también explican esa persistencia. Por ejemplo, la costumbre, las confianzas, las relaciones de parentesco o simplemente el no creer que sea posible, revelando en esta última condición un imaginario que sitúa al pescador artesanal y a "su mundo" en un lugar determinadamente subordinado. Desde esta premisa no deja de tener sentido la tesis de Godelier respecto del profundo arraigo ideomaterial de las relaciones [sociales] de producción, y del "pensamiento consciente" como base de toda transformación social.

La intermediación, en los sistemas pesquero-artesanales del sur austral de Chile, es un tipo de estructuración profunda que presenta variaciones históricas y territoriales. Históricamente arraigada, su persistencia debe observarse identitaria y culturalmente a partir de un entramado de representaciones complejas propias de la modulación de los sistemas sociales que devienen en el marco de matrices simbólicas situadas incluso más allá de las voluntades cotidianas de sus protagonistas. Dicho de otro modo, el problema de la intermediación en las economías de pesca artesanal remite a la pregunta por la transformación del orden social y económico. Esta última consideración remite, sin lugar a duda, a la dimensión político-cultural de la economía. Tal vez de la economía política de la pesca artesanal, en el sur de Chile y en todas partes.

\section{Agradecimientos}

Este trabajo ha sido desarrollado en el marco de los proyectos de investigación FONDECYT Regular 1171309: "Condicionamientos socio-ambientales y económico-culturales de la producción y la intermediación en el espacio pesquero artesanal chileno. Una investigación antropológica sobre los límites de la transformación social" y DID UACH N ${ }^{\circ}$ S-201546: "Producir, intercambiar, vivir: Economía y cultura en dos sociedades litorales del sur austral de Chile". Agradecemos el valioso apoyo del programa FONDECYT y de la Universidad Austral de Chile. Nuestro reconocimiento y gratitud a las mujeres y hombres, pescadores, de Las Guaitecas, Quellón y Calbuco. A las y los evaluadores de Estudios Atacameños por sus valiosos comentarios.

\section{Referencias citadas}

Acuña Plavan, A., y Verocai, J. E. (2001). Importancia de la pesquería artesanal y biología de la brótola, Urophycis brasiliensis (Kaup, 1858) (Phycidae, Gadiformes) en la costa uruguaya. Investigaciones marinas, 29(1), 47-58.

Alcalá, G. (1993). Migrantes, Pescadores y mujeres en Puerto Madero, Chiapas, México, Mesoamérica, 14(25), 101-114.

Alioune, S. y Catanazo, J. (2005). Self-regulation of Senegalese artisanal fisheries: A case study of Kayar. Successful Fisheries Management: Issues Case Studies and Perspectives, 149-169.

Appadurai, A. (1986). La vida social de las cosas. Perspectiva cultural de las mercancías. México, DF: Grijalbo.

Appadurai, A. (2015). El futuro como hecho cultural. México: Fondo de Cultura Económica.

Ávalos, P. (2006). Los impactos socioespaciales en las caletas de pescadores artesanales de la comuna de Corral en el marco de la legislación pesquera promulgada entre los años 19902005. Memoria para optar al título profesional de Geógrafo. Escuela de Geografía, Facultad de Arquitectura y Urbanismo, Universidad de Chile.

Balbi, F. (2008). Sobre la presunta 'lógica interna' de una forma 'no capitalista' de producción: el caso de los pescadores comerciales del Delta paranaense entrerriano en 
la década del 1980. En Bolvin, M., Rosato, A. y Balbi, F. Calando la vida: Ambiente y pesca artesanal en el Delta entrerriano. Buenos Aires: Editorial Antropología, Serie "Antropología Política y Económica" - GIA-PER.

Barton, J. y Román, A. (2016). Sustainable development? Salmon aquaculture and late modernity in the archipelago of Chiloé, Chile. Island Studies Journal, 11(2), 651-672.

Bird-David, N. (1997). Las economías: una perspectiva económico cultural. Revista Internacional de Ciencias Sociales, 154. UNESCO.

Boivin, M. y Rosato, A. (2011). Antropologías nacionales, antropología propia y formación antropológica: Comentarios desde Argentina. Alteridades, 21(41), 99-102.

Bourdieu, P. (1980). El sentido práctico. Madrid: Taurus.

Bourdieu, P. (2003). Las estructuras sociales de la economía. Barcelona: Anagrama.

Braudel, F. (1985). La dinámica del capitalismo. Madrid: Alianza.

Brinck, G., Plá, R. y Morales, C. (2011). La merluza austral. Economía y vida social en Puerto Gala. En Alcalá, G. (Coord.). Pescadores en América Latina y El Caribe. México, DF: UNAM.

Bustos, B. e Irarrazaval, F. (2016). “Throwing money into the sea": capitalism as a world-ecological system. Evidence from the Chilean salmon industry crisis, 2008. Capitalism Nature Socialism, 27(2), 1-20.

Byron, J. (1955). El naufragio de la fragata Wager. Santiago: Zig-Zag.

Castañeda, T., Boucher, F., Sánchez, E. y Espinoza, A. (2009). "La concentración de agroindustrias rurales de producción de quesos en el noroeste del Estado de México: un estudio de caracterización”. Estudios sociales (Hermosillo, Son.), 17(34), 73-109.

Cavada, F. (1914). Chiloé y los Chilotes. Revista Chilena de Historia y Geografía. Año II, III(7), 362-462.

Comaroff, J. L. y Comaroff, J. (2011). Etnicidad S.A. Madrid: Katz.

Comas d'Argemir, D. (1997). Antropología económica. Barcelona: Ariel.
Cunningham, S. y Bostock, T. (2005). Successful Fisheries Management. Issues, Case Studies and Perspectives. Amsterdam: Eburon.

De Beranger, C. (1893 [1773]). Relación Jeográfica de la Isla de Chiloé, Introducción de Nicolás Anrique, 1893. Santiago: Anales de la Universidad de Chile.

De Laire, F. (2001). ¿Está Chile o no por la sustentabilidad de la pesca artesanal? Revista Ciencias Sociales, 11, 99-122.

Domenach, J. M. (1980). Crisis del desarrollo, crisis de la racionalidad. En Attali, J., Castoriadis, C., Domenach, J. M., Massé, P., Morin, E. et al. El mito del desarrollo (pp. 13-42). Barcelona: Kairós.

Elías, B. y Devisscher, M. (2014). "Prescindir del intermediario: un sueño campesino”. En Elías, B. y Devisscher, M. (Eds.). Del productor al consumidor. Una alternativa para la agricultura familiar (pp. 17-31). La Paz: Agrónomos y Veterinarios sin Fronteras.

Escobar, A. (1996). La invención del Tercer Mundo. Construcción y deconstrucción del desarrollo. Bogotá: Norma.

Escobar, A. (2010). Territorios de diferencia: lugar, movimientos, vida, redes. Bogotá: Envión.

Florido del Corral, D. (2008). Las flotas artesanales andaluzas en un contexto de crisis. En González Laxe, F. (Ed.). Lecciones de economía pesquera. La Coruña: Netbiblo.

Forero, J. (2012). La comercialización agrícola y las cooperartivas rurales dentro del programa DRI en Colombia. Cuadernos de Desarrollo Rural, 27.

Friedman, J. (1994). Identidad cultural y proceso global. Buenos Aires: Amorrortu.

Gajardo, C., y Ther, F. (2011). Saberes y prácticas pesqueroartesanales: cotidianeidades y desarrollos en las caletas de Guabún y Puñihuil, Isla de Chiloé. Chungara. Revista de Antropología Chilena, 43, 589-605.

García, J., S.J. (1889). Diario de la navegación hechos por el padre José García de la Compañía de Jesús, desde su misión de Cailín, en Chiloé, hacia el sur, en los años 17661767. Anuario Hidrográfico de la Marina de Chile, Vol. $X I V$. Santiago: Imprenta Nacional. 
García Allut, A. G. y Vásquez Portela, E. (2012). Nueva gobernanza de los ecosistemas costeros: una propuesta metodológica. V. 4.28. I Congreso Iberoamericano de Gestión Integrada de Áreas Litorales.

García Canclini, N. (1990). Culturas Hibridas. Estrategias para entrar y salir de la modernidad. México, DF: Grijalbo.

Gelcich, S., Edwards-Jones, G., Kaiser, M. J. y Watson, E. (2005). Using discourses for policy evaluation: the case of marine common property rights in Chile. Society and Natural Resources, 18(4), 377-391.

Godelier, M. (1990). Lo idealy lo material. Madrid: Taurus.

González Casanova, P. (2006). El colonialismo interno. En Sociología de la explotación. Buenos Aires: CLACSO.

Grass, J., Cervantes, F. y Altamirano, J. (2013). Estrategias para el rescate y valorización del queso tenate de Tlaxco: Un análisis desde el enfoque de sistemas agroalimentarios localizados (SIAL). Culturales, 1(2), 9-54.

Gudeman, S. (2000). The Anthropology of Economy: Community, Market, and Culture. Malden, MA: Blackwell.

Gudeman, S. y Rivera, A. (1990). Conversations in Colombia: The Domestic Economy in Life and Text. Cambridge, MA: Cambridge University Press.

Harvey, D. (2007). Breve historia del neoliberalismo. Madrid: AKAL.

Herskovits, M. (1954). Antropología económica. Estudios de economía comparada. México, DF: Fondo de Cultura Económica.

Hinkelammert, F. (2001). El nihilismo al desnudo. Los tiempos de la globalización. Santiago: LOM.

Hinkelammert, F. y Mora, H. (2005). Hacia una economía para la vida. Asociación Departamento Ecuménico de Investigaciones, San José de Costa Rica.

Leff, E. (1998). Saber ambiental. Sustentabilidad, racionalidad, complejidad, poder. México, DF: CEIICH- UNAM - Siglo XXI Editores - PNUMA.

Leff, E. (2010). Discursos sustentables. México: Siglo XXI.

Long, N. (2007). Sociología del desarrollo: una perspectiva centrada en el actor. México, DF: COLSAN - CIESAS.
Macías, A. y Alonso, P. (2015). Collective symbolic capital and sustainability: Governing fishing communities in a knowledge economy. Marine Policy, 53, 21-26.

Malinowski, B. (2001). Los argonautas del Pacifico Occidental: comercio y aventura entre los indigenas de la Nueva Guinea Melanésica. Madrid: Península.

Marín, G. (2003). La pesca en la costa de Michoacán: una visión de conjunto. En Alcalá, G. et al. Espacio y actividades costeras en Michoacán: una aproximación multidisciplinaria. México: El Colegio de México, El Colegio de Michoacán y Centro de Investigaciones Científicas y Estudios Superiores de Ensenada.

Marín, W. (2007). Cultura y modernización de la pesca artesanal en Chile: adaptaciones, cambios e hibridaciones en una caleta de Algueros. Revista MAD, 17, 113-143.

Martinic, M. (2005). De la Trapananda al Aysén. Una mirada reflexiva sobre el acontecer de la Región de Aysén desde la Prehistoria hasta nuestros días. Santiago: Pehuén.

Mignolo, W. (2003). Historias locales / diseños globales. Colonialidad, conocimientos subalternos y pensamiento fronterizo. Madrid: Akal.

Montañés, M. (2010). El grupo de discusión. Cuadernos CI$M A S$. Madrid: Red CIMAS.

Morales, C. (2012). Dos seres Marinos/Febriles Mercancias de Exportación. La formación de Puerto Gala y la transformación de Apiao. Estudio comparativo. Tesis para optar al grado de Licenciado en Antropología Social y título de Antropólogo Social, Universidad Academia de Humanismo Cristiano, Santiago, Chile.

Morales, D. (2014). El negocio de la madera: comerciantes y "hacheros" de Chiloé, 1850-1875. Magallania, 42(2), 41-60.

Morandé, P. (1987). Cultura y modernización en América Latina. Santiago: Universidad Católica de Chile.

Neira, P. (2005). Las comunidades de pescadores artesanales frente a la modernización: el caso de Caleta Queule. Memoria para optar al título de Antropóloga, Universidad de Chile.

Núñez, A., Molina, R., Aliste, E. y Bello, Á. (2016). Silencios geográficos de Patagonia-Aysén: Territorio, nomadismo y perspectivas para re-pensar los márgenes de la nación en el siglo XIX. Magallania, 44(2), 107-130. 
Otero, L. (2006). La huella del fuego. Historia de los bosques nativos. Poblamiento y cambios en los paisajes del sur de Chile. Santiago: Pehuén.

Pedroza, C. y Salas, S. (2011). Responses of the fishing sector to transitional constraints: From reactive to proactive change, Yucatan fisheries in Mexico. Marine Policy, 35, 39-49.

Perea, E. (2016). El ser proveedor: La construcción social de la maculinidad entre los pescadores de Sisal, Yucatán. Tesis para obtener la Licenciatura en Desarrollo y Gestión Interculturales, Universidad Nacional Autónoma de México, México.

Polanyi, K. (2009). El sustento del hombre. Madrid: Capitán Swing.

Pollnac, R. (1995). Las características sociales y culturales del desarrollo pesquero en pequeña escala. En Cernea, M. (Comp.). Primero la gente (pp. 305-346). México, DF: Fondo de Cultura Económica.

Rebollar, R., Hernández, M., González, R., García, M., Albarrán, P. y Rojo, R. (2011). Canales y márgenes de comercialización del queso añejo en Zacazonapan, México. Archivos de Zootecnia, 60, 883-889.

Rementería, I. (1981). La economía campesina y el mercado agropecuario. Estudios Rurales Latinoamericanos, 4(3).

Rodríguez Bravo, A., Montolla Vilar, N. y Mas Manchón, L. (2011). Plan Integral de Comunicación para un sector económico en crisis: Estudio de caso de la Comunidad de Pescadores de Corumbá (MS, Brasil). Revista Brasileira de Ciências da Comunicação, 34(2), 93-116.

Saavedra, G. (2011). Perspectivas Culturales del Desarrollo en las Costas Australes de Chile. Aproximación antropológica a las persistencias y transformaciones de las economias de pesca artesanal en el litoral de Aisén. Tesis doctoral, Dpto. Ciencia Política y de la Administración III, Universidad Complutense de Madrid, Madrid.

Saavedra, G. y Navarro, M. (2016). El Sur-austral en movimiento: Itinerarios chilotes en Patagonia insular occidental. En Kottow, A. y Traverso, A. (Eds.). Diálogos
culturales/Imaginarios nacionales: Viajes, territorios e identidades (pp. 139-15). Santiago: RIL.

Sáez, L., Adofacci, G. y Maino, M. (2012). Caracterización de la cadena de comercialización de la langosta del Archipiélago Juan Fernández. Avances en Ciencias Veterinarias, $27(1)$.

Sahlins, M. (1972). Economía de la edad de piedra. Madrid: Akal.

Sahlins, M. (1988). Islas de historia: la muerte del capitán Cook, metáfora, antropología e historia. Barcelona: Gedisa.

Sandoval, V. y Ruiz, R. (2006). El rol de los recursos locales en la evolución de la agroindustria rural del almidón de yuca en el departamento del Cauca, Colombia. Agroalimentaria, 22, 41-47.

Thompson, D. (2007). Economía e identidad de los pescadores de la Barra de la Laguna de Rocha. Anuario de Antropología Social y Cultural en Uruguay. Romero Gorski, S. (Comp. y Ed.). Montevideo: Nordan.

Torres Salcido, G. (2013). Sistemas agroalimentarios localizados. Innovación y debates desde América Latina. Revista Internacional Interdisciplinar INTERthesis, 10(2), 68-94.

Urbina, M. X. (2011). Análisis histórico-cultural del alerce en la Patagonia Septentrional Occidental, Chiloé, Siglos XVI al XIX. Magallania 39(2), 57-73.

Wallerstein, I. (1998). El capitalismo histórico. México, DF.: Siglo XXI.

Wallerstein, I. (2005). Análisis del sistema mundo. México, DF: Siglo XXI.

Wolf, E. (1987). Europa y la gente sin historia. México, DF: Fondo de Cultura Económica.

Zamora, A. (2011). Pescadores artesanales de Valparaíso, Chile. Subsistema económico, "sociedad a la parte" y crisis en la pesquería de la merluza común. En Alcalá, G. (Coord.). Pescadores en América Latina y El Caribe. México, DF: UNAM. 